\title{
Psychometric Features of Children Life Styles Inventory
}

\author{
Ahmet Ragıp ÖZPOLAT ${ }^{1, *}$, İsa Yücel İŞGÖR ${ }^{1}$, Sırrı AKBABA ${ }^{2} \&$ Ahmet YİĞİT ${ }^{2}$ \\ ${ }^{1}$ Department of Educational Sciences, Psychological Counseling and Guidance, Erzincan University, Turkey \\ ${ }^{2}$ Department of Educational Sciences, Psychological Counseling and Guidance, Bursa University, Turkey \\ *Correspondign author: Department of Educational Sciences, Psychological Counseling and Guidance, Erzincan \\ University, Turkey Tel: 90-505-511-7132 E-mail: ahmetozpolat@hotmail.com
}

Received: January 11, 2013

Accepted: February 2, 2013

Online Published: April 16, 2013

doi:10.5430/wje.v3n2p50

URL: http://dx.doi.org/10.5430/wje.v3n2p50

\begin{abstract}
Children Life Styles Inventory was developed by Stiles \& Wilborn and in this study, Psychometric features of the inventory in Turkey is researched. At the end of the study, it was found that correlation coefficient among original and applied form points was .87 for linguistic equivalence. Structural and consistence validity of Turkish form were analyzed. At the end of explanatory factor analysis, it was found that Children Life Style Inventory has 6 factors like in its original form and items in sub-factors coincided with the items in original inventory. On the other hand, for consistence study of Children Life Styles Inventory, original scale was taken into consideration. Scale's data in terms of Turkish reliability and validity were also positive. At the end of DFA, it was found that $\chi^{2}$ (938.94) sd (290) $(\chi$ 2/sd=3.23), RMSEA (.07) RMR (.08) SRMR (.07) GFI (.95) AGFI (.93) CFI (96)
\end{abstract}

Keywords: life styles; individual psychology; childhood experiences

\section{Introduction}

Life Styles is rooted from child's power of creation, how he sees the world and what he sees as success (Adler, 1993). Newborn make use of his experiences while creating concepts about the world he was born into and learn his environment. This learning process is the result of child's experiences at the end of his trial and error process aimed at learning his environment. These experiences cause him develop rules about the world. These rules enable the child create a point of view about the world and give meaning to it. As a result, this set of rules become original life principals of individuals and they define original life styles of individuals (Shulman \& Mosak, 1988). Life styles are not only affected from childhood experiences but also from the individuals' physical development (Adler, 1993). According to Adler, life styles have biological-psychological and social features. For example lack of an organ means biological or physical disadvantage and it is one of the most significant factors that affect lifestyle of individuals. Family, friends, teachers are the other significant factors that have role on individuals' life styles besides environmental effects, neighbors and culture.

Adler grouped lifestyles under four headings. Ruling Type; these individuals are normative and they force others obey these rules. Managers generally belong to this group. Getting Type; individuals that have this lifestyle do not give effort for anything, they want others to do everything. Avoiding Type; these individuals don't want responsibilities in their lives and they have poor social relations. Socially Useful Type; they have strong social relations and they can make cooperation (Adler, 1964). Stiles developed children life styles inventory in 1992 by taking Adler's views into consideration. This inventory is 5 point likert type and it has 6 factors: Socially useful; individuals have good relations with others and they have social life styles. These individuals are described as social individuals in their lives. This life style was developed according to Adler's Socially Useful type life style. Pleasing Lifestyle; these individuals need to take others' opinions and approval for everything in their lives and they act according to others. Controlling life style; these individuals try to control everything in their lives and around them and they have dominant roles on people with whom they communicate. This life style is inspired by Adler's Ruling Type model. Getting Life Style; it is similar with Adler's Getting Type Life Style. These individuals depend on others, they are very shy, they can not make decisions on their own and they can be used by others. Inadequacy Life Style has some similarities with Adler's Avoiding type Life Style. They avoid communicating with others. When they face 
a problem, they step back and accept the situation rather than making cooperation with others and try to overcome the situation. Rebelling has similarities with Adler's Ruling Type model. Individuals that have this lifestyle are rebellious; they don't want to obey the rules set by others (Arnold, 1996). There are many surveys about life styles in the literature (Kern et al. 1984, Langenfeld, 1981,), but most of these are for adults (Allen, 2005). However, early childhood experiences are very important in forming the life style of an individual (Kopp \& Eckstein, 2004, Kern et al., 2004; Lewis \& Olson, 2011). First life styles inventory was developed by Stiles (1992) by taking this point of view into consideration. The aim of this study is to research psychometric features of this inventory in Turkey.

\section{Method}

\subsection{Study Group}

This research was made on 451 students chosen from various schools' $8^{\text {th }}$ grade. The schools are in a city that has 80.000-100.000 population and the city is on the east of Turkey. Sampling of the research included 251 female, 200 male students, the age range of most of the sampling (\%94) was 14-16, and average age was 15.

\subsection{Data Collection Tool}

Children Life Styles Inventory is made of 90 items and inspired from Adlerian concepts. The inventory has six sub dimensions. These are: Pleasing, Rebelling, Getting, Controlling, Inadequacy and Socially Useful. Inventory was conducted on students at 8-11 years old group; cronbach alpha coefficient for sub inventories were: Pleasing, (.70) Rebelling,(.76) Getting,(.76) Controlling,( .61) Inadequacy (,74) and Socially Useful.( .65). test retest results of sub inventories were meaningful ( $\mathrm{p}<.05$ significance level) and they are respectively: Pleasing, (.72) Rebelling,(.75) Getting,(.76) Controlling,( .71) Inadequacy (,73) and Socially Useful.( .72), (Stiles \& Wilborn, 1992).

\subsection{Process}

In the process of adapting Children Life Styles Inventory, firstly the English form was translated into Turkish. In order to evaluate translation and develop the trial form of inventories, "Re-Translation Method" was used and "One Way Translation" was made. Translation and control of Children Life Styles Inventory from English to Turkish were made by researchers and 4 academic members of English Language Department. Views of two academic members (who know English) in the Psychological Counseling and Guidance department on the inventory (with their English translations) were taken into consideration. The developed Turkish form was given to two academic members of English Teaching Department who could use both languages fluently and they were retranslated. At the end of this re-translation, Turkish trial form, which was believed to present the original form well, was prepared. This trial form was applied in two sessions on $1518^{\text {th }}$ grade students in the private school in a city that has $40.000-50.000$ population. In the first session, English original forms of the scale were given to students and they were required to answer all of the questions without any exception. 30 minutes later, $2^{\text {nd }}$ session started and Turkish forms of the scale were given to the students and they were required to fill the form. Correlation between these two applications was taken as the standard of linguistic equivalence.

Item test correlation and \%27 subgroup and super-group comparisons for item distinguishing of Children life Styles Inventory were used. In the evaluation of item test correlation, Paerson product-moment correlation coefficient was determined according to total point and t-test was used in comparing \%27 sub and super-groups. Internal consistency and test re-test reliability study for reliability studies were made with $4518^{\text {th }}$ grade students. Turkish forms were applied on these students two times with 15-day break in between and correlation between the data of two applications were used as test retest reliability coefficient.

Structural and consistence validity were analyzed for validity studies of Children Life Styles Inventory. Explanatory and confirmatory factor analyses were applied for researching structural validity of the inventory. The inventory was compared with the original one in order to determine the consistence validity and the result was accepted to be the consistence validity. SPSS 15.0 and Lisrel 8.51 programs were used in order to understand the reliability and validity of the inventory.

\subsubsection{Linguistic Equivalence}

Correlations between English and Turkish form points were calculated in order to determine the linguistic equivalence of inventory and it was found that; for the complete scale .87, for Pleasing sub scale (.85) for Rebelling sub scale (.76) for Getting sub scale (.79) for Controlling sub scale (.80) for Inadequacy sub scale (.77) and for Socially Useful sub scale alt (.86) $(\mathrm{p}<.05$ significance level). 


\subsubsection{Reliability}

Corrected Item-Total point correlation of $13^{\text {th }}, 14^{\text {th }}, 16^{\text {th }}, 26^{\text {th }}, 27^{\text {th }}, 30^{\text {th }}, 31^{\text {st }}, 37^{\text {th }}, 80^{\text {th }}, 82^{\text {nd }}$ and $83^{\text {rd }}$ items of Children Life Styles Inventory were found to be meaningless. Children Life Styles Inventory's $44^{\text {th }}, 49^{\text {th }}, 53^{\text {rd }}, 56^{\text {th }}$ and $79^{\text {th }}$ items' corrected Item-Total point correlation was low and it was found that if these items were deleted, Cronbach Alpha coefficient value would increased up to .94 . These findings show that $13^{\text {th }}, 14^{\text {th }}, 16^{\text {th }}, 26^{\text {th }}, 27^{\text {th }}, 30^{\text {th }}$, $31^{\text {st }}, 37^{\text {th }}, 38^{\text {th }}, 80^{\text {th }}, 82^{\text {nd }}$, and $83^{\text {rd }}$ items had adverse effect on the scale while $44^{\text {th }}, 49^{\text {th }}, 53^{\text {rd }}, 56^{\text {th }}$ and $79^{\text {th }}$ items had little contribution to the scale. As a result, $13^{\text {th }}, 14^{\text {th }}, 16^{\text {th }}, 26^{\text {th }}, 27^{\text {th }}, 30^{\text {th }}, 31^{\text {st }}, 37^{\text {th }}, 38^{\text {th }}, 44^{\text {th }}, 49^{\text {th }}, 53^{\text {rd }}, 56^{\text {th }}, 79^{\text {th }}, 80^{\text {th }}$, $82^{\text {nd }}$, and $83^{\text {rd }}$ items were removed from the scale. Total internal consistency reliability coefficient was found to be .94 for the complete inventory. Cronbach alpha coefficient for Pleasing sub scale was .92, Cronbach alpha coefficient for Rebelling sub scale was .90, Cronbach alpha coefficient for Getting sub scale was .92, Cronbach alpha coefficient for Controlling sub scale was .93 Cronbach alpha coefficient for Inadequacy sub scale was .91 and Cronbach alpha coefficient for Socially Useful sub scale was .94. Test retest reliability coefficient for the complete scale was found to be .88 , for Pleasing sub scale .87 , for Rebelling sub scale .79 , for Getting sub scale .80 , for Controlling sub scale .85 for Inadequacy sub scale .80 and for Socially Useful sub scale .88 .

\subsubsection{Structural Validity}

Explanatory and confirmatory factor analyses were made in order to analyze the structural validity of the inventory. Firstly, sampling coherence and Barlett Sphericity Tests were made. Data are accepted to be consistent with the factor analysis, KMO needs to be higher than .60 and Barlett test should be meaningful (Büyüköztürk, 2004). In this research, KMO sampling consistency coefficient was .93 and Barlett Sphericity test $\mathrm{X}^{2}$ value was 87455,607 $(\mathrm{p}<.001)$. These results show that items given to the inventory answers can be accepted as factors.

As the original Children Life Styles Inventory was made of 6 sub dimensions, basic component analysis and varimax rotation was limited with 6 factors. At the end of this process, a structure with 6 factors that can explain $\% 90$ of total variance was formed. It was seen that item distributions in the original form and in the adapted version were consistent. Factor results and factor loads are presented in Table 1.

Table 1: Children Life Styles Inventory Explanatory Factor Analysis Results

\begin{tabular}{|c|c|c|c|c|c|c|}
\hline Item & SU & $\mathrm{P}$ & C & G & 1 & $\mathrm{R}$ \\
\hline 11 & 0,977 & & & & & \\
\hline 15 & 0,974 & & & & & \\
\hline 2 & 0,971 & & & & & \\
\hline 20 & 0,970 & & & & & \\
\hline 25 & 0,970 & & & & & \\
\hline 33 & 0,969 & & & & & \\
\hline 41 & 0,965 & & & & & \\
\hline 43 & 0,965 & & & & & \\
\hline 45 & 0,964 & & & & & \\
\hline 6 & 0,957 & & & & & \\
\hline 65 & 0,954 & & & & & \\
\hline 7 & 0,953 & & & & & \\
\hline 74 & 0,943 & & & & & \\
\hline 84 & 0,931 & & & & & \\
\hline 90 & 0,914 & & & & & \\
\hline 1 & & 0,973 & & & & \\
\hline 12 & & 0,969 & & & & \\
\hline 23 & & 0,967 & & & & \\
\hline 28 & & 0,965 & & & & \\
\hline 40 & & 0,965 & & & & \\
\hline 51 & & 0,965 & & & & \\
\hline 54 & & 0,965 & & & & \\
\hline 57 & & 0,964 & & & & \\
\hline 58 & & 0,964 & & & & \\
\hline 59 & & 0,963 & & & & \\
\hline 62 & & 0,936 & & & & \\
\hline 73 & & 0,935 & & & & \\
\hline
\end{tabular}




\begin{tabular}{|c|c|c|c|c|c|}
\hline 77 & 0,909 & & & & \\
\hline 8 & 0,877 & & & & \\
\hline 17 & & 0,956 & & & \\
\hline 22 & & 0,944 & & & \\
\hline 3 & & 0,938 & & & \\
\hline 36 & & 0,934 & & & \\
\hline 4 & & 0,931 & & & \\
\hline 5 & & 0,930 & & & \\
\hline 52 & & 0,928 & & & \\
\hline 63 & & 0,905 & & & \\
\hline 64 & & 0,904 & & & \\
\hline 67 & & 0,901 & & & \\
\hline 76 & & 0,899 & & & \\
\hline 81 & & 0,893 & & & \\
\hline 86 & & 0,885 & & & \\
\hline 88 & & 0,841 & & & \\
\hline 32 & & & 0,943 & & \\
\hline 34 & & & 0,941 & & \\
\hline 39 & & & 0,941 & & \\
\hline 48 & & & 0,933 & & \\
\hline 55 & & & 0,928 & & \\
\hline 60 & & & 0,923 & & \\
\hline 66 & & & 0,921 & & \\
\hline 71 & & & 0,910 & & \\
\hline 87 & & & 0,907 & & \\
\hline 89 & & & 0,902 & & \\
\hline 9 & & & 0,852 & & \\
\hline 18 & & & & 0,921 & \\
\hline 21 & & & & 0,920 & \\
\hline 24 & & & & 0,920 & \\
\hline 47 & & & & 0,908 & \\
\hline 61 & & & & 0,907 & \\
\hline 69 & & & & 0,901 & \\
\hline 72 & & & & 0,899 & \\
\hline 75 & & & & 0,897 & \\
\hline 78 & & & & 0,885 & \\
\hline 85 & & & & 0,885 & \\
\hline 10 & & & & & 0,940 \\
\hline 19 & & & & & 0,933 \\
\hline 29 & & & & & 0,922 \\
\hline 35 & & & & & 0,901 \\
\hline 42 & & & & & 0,900 \\
\hline 46 & & & & & 0,897 \\
\hline 50 & & & & & 0,892 \\
\hline 68 & & & & & 0,864 \\
\hline 70 & & & & & 0,859 \\
\hline
\end{tabular}

When table 1 is analyzed, it can be seen that items under the group of "Socially Useful sub scale" include individuals' relations with others and social life style. Individuals that get high points in this sub-scale are generally defined as social people in their lives. This factor, whose factor loads change between .97 and .91 , explains $\% 20.30$ of total variance and is made of 15 items. One of the example of this factor's items can be "I take part in social activities". The second factor Pleasing sub-scale is made of 14 items. Individuals who take high points from this scale are the ones that want to take others' opinions and approval and behave according to them. This factor, whose factor loads change between .97 and .87 , explains \% 18.65 of total variance. One of the example of this factor's items can be " $I$ 
get said if I learn that somebody doesn't like me". Individuals in the group of the third factor controlling sub-scale want to take control of everything in their lives. They dominate people with whom they communicate. This factor, whose factor loads change between .95 and .84 , explains $\% 16.64$ of total variance and it is made of 14 items. One of the example of this factor's items can be "I change rules when I don't like the game we play". Points taken from the fourth factor Getting sub-scale show that individual depends on others. These individuals are timid, they can not make decisions and they may be used by others. This factor, whose factor loads change between .94 and .85 , explains \% 13.27 of total variance and it is made of 11 items. One of the example of this factor's items can be "I make mistakes because of others". The fifth factor is Inadequacy sub-scale. Individuals that have this life style avoid communicating with others. Instead of cooperating with others in order to solve problems, they retreat and accept the situation. This factor, whose factor loads change between .92 and .88 , explains $\% 11.55$ of total variance and it is made of 10 items. One of the example of this factor's items can be "I generally say no when my friends say 'Let's play a game or go somewhere"'. The sixth factor is Rebelling sub-scale. Individuals that have this lifestyle do not obey the rules set by others and they are rebellious. This factor, whose factor loads change between .94 and .85 , explains \% 10.37 of total variance and it is made of 9 items. One of the example of this factor's items can be "I am sent to discipline board of the school many times (as I don't obey the rules)". On the other hand, in order to confirm the factor structure of Children Life Styles Inventory, data were analyzed through Lisrel 8.55 program. Some consistence statistics results were used in order to understand if the scale is verified or not in the confirmatory factor analysis. Commonly used of these consistence statistics is Chi Square. If chi square's ratio to degree of freedom is two or below, it means perfect consistence; if it is between two and five, this means an acceptable consistence. The others are GFI (Goodness of fit index), AGFI (Adjusted Goodness of fit index), CFI (Comparative fit index), RMSEA (Root mean square error of approximation), RMR (Root mean square residual) and SRMR (Standardized root mean square residual); if GFI, AGFI and CFI are higher than .90, it means an acceptable consistence. If RMSEA, RMR, SRMR values are .05, it means a good consistence; if it is below .08, it means an acceptable consistence (Jöreskog, 1969, Şimşek, 2007).

At the end of confirmatory factor analysis of Children Life Styles Inventory, it was found out that $\chi^{2}$ is (938.94) sd (290) $\left(\chi^{2} / \mathrm{sd}=3.23\right)$, RMSEA (.07) RMR (.08) SRMR (.07) GFI (.95) AGFI (.93) CFI (96). This consistence shows that the scale is confirmed in terms of structure. Path diagram of the scale is given in Table 2.

\subsubsection{Consistence Validity}

Firstly, original scale was analyzed in order to start the study of consistence validity of Children Life Styles Inventory. Original scale's Pleasing sub scale cronbach alpha coefficient was found to be .70, Rebelling sub scale cronbach alpha coefficient was found to be .76, Getting sub scale cronbach alpha coefficient was found to be .76, Controlling sub scale cronbach alpha coefficient was found to be .61, Inadequacy sub scale cronbach alpha coefficient was found to be .74 and Socially Useful sub scale cronbach alpha coefficient was found to be 65 (Stiles $\&$ Wilborn, 1992). These values in Turkish reliability and validity study were; Pleasing sub scale cronbach alpha coefficient .92, Rebelling sub scale cronbach alpha coefficient .90, Getting sub scale cronbach alpha coefficient .92, Controlling sub scale cronbach alpha coefficient .93, Inadequacy sub scale cronbach alpha coefficient .91, and Socially Useful sub scale cronbach alpha coefficient .94. Inventory's test retest reliability coefficient for the whole scale.88, for Pleasing sub scale .72, Rebelling sub scale .75, Getting sub scale .76, Controlling sub scale .71 Inadequacy sub scale .73, Socially Useful sub scale .72 (Stiles \& Wilborn, 1992). These values in Turkish reliability and validity study were; Pleasing sub scale .87 , Rebelling sub scale.79, Getting sub scale .80 , for Controlling sub scale .85 , Inadequacy sub scale .80 , and Socially Useful sub scale .88 .

The inventory had given better data in Turkish reliability and validity studies. 
Table 2: Child Life Styles Inventory Path Diagram

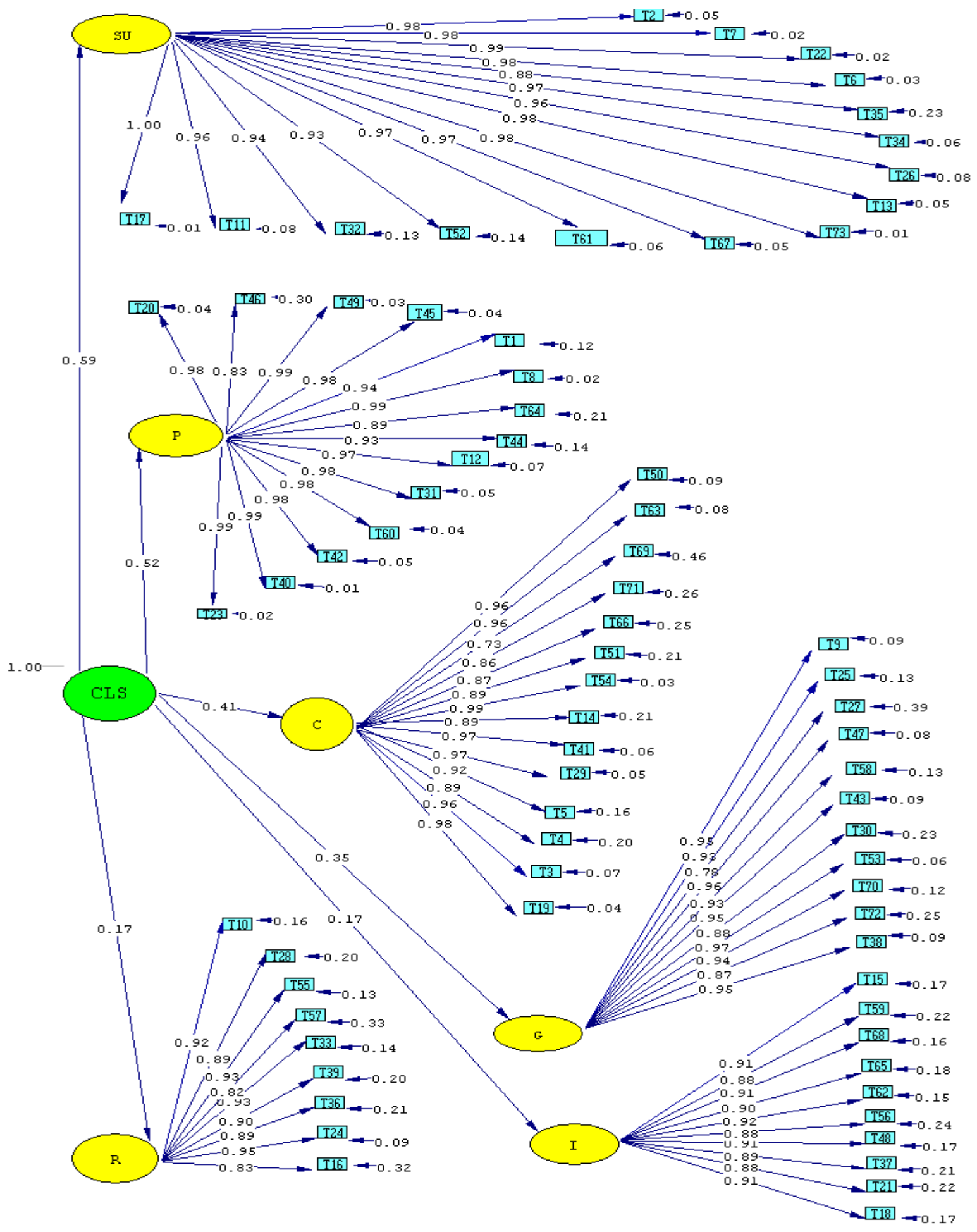




\subsubsection{Item Analysis}

Item total test correlation explains the relation between the points of test items and total point of the test. According to this, item total test correlations are expected to be positive and high (Baykul, 2000). In the interpretation of item test correlation, it is accepted that items that are 30 and higher distinguish individuals in terms of the evaluated feature (Büyüköztürk, 2004).

It was found out that Children Life Styles Inventory's corrected item-total point correlation was between .31 and .74; inventory's $\mathrm{t}(\mathrm{sd}=327)$ values according to the differences between the points of $\% 27 \mathrm{sub}$ and super groups that were determined according to total points were between $10.01(\mathrm{p}<.01)$ and $73.43(\mathrm{p}<.01)$. Findings are given in Table-3.

Table 3: Corrected Item test Correlations of Life Styles Inventory and t Values of \%27 Sub and Super Groups

\begin{tabular}{|c|c|c|c|c|c|c|c|c|c|c|c|}
\hline Sub & & & & Sub & & & & Sub & & & \\
\hline Scale & Item No & $r_{j x}$ & $\mathbf{t}$ & Scale & Item No & $\mathbf{r}_{\mathbf{j x}}$ & $\mathbf{t}$ & Scale & Item No & $\mathbf{r}_{\mathrm{jx}}$ & $\mathbf{t}$ \\
\hline \multirow{15}{*}{ 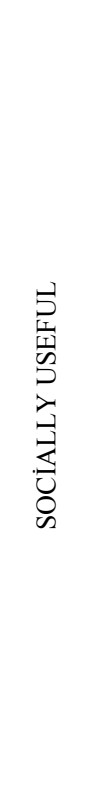 } & 2 & $0,54(*)$ & 63,81 & \multirow{15}{*}{ 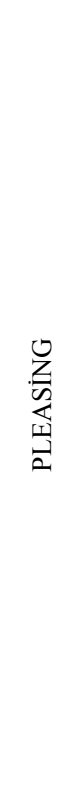 } & 1 & $0,57(*)$ & 13,81 & \multirow{15}{*}{ 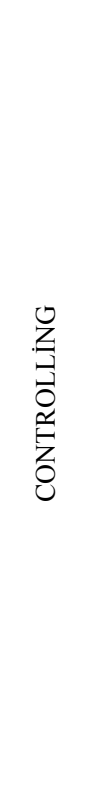 } & 3 & $0,64\left(^{*}\right)$ & 16,29 \\
\hline & 6 & $0,71\left(^{*}\right)$ & 62,52 & & 8 & $0,69\left(^{*}\right)$ & 17,34 & & 4 & $0,41\left(^{*}\right)$ & 10,25 \\
\hline & 7 & $0,71\left(^{*}\right)$ & 50,91 & & 12 & $0,62\left(^{*}\right)$ & 16,25 & & 5 & $0,46(*)$ & 11,23 \\
\hline & 11 & $0,67(*)$ & 43,16 & & 20 & $0,68\left(^{*}\right)$ & 17,82 & & 14 & $0,46(*)$ & 10,71 \\
\hline & 13 & $0,67\left(^{*}\right)$ & 43,03 & & 23 & $0,65\left(^{*}\right)$ & 16,88 & & 19 & $0,63(*)$ & 16,25 \\
\hline & 17 & $0,74\left(^{*}\right)$ & 17,48 & & 31 & $0,58\left(^{*}\right)$ & 15,15 & & 29 & $0,65\left(^{*}\right)$ & 15,85 \\
\hline & 22 & $0,72(*)$ & 73,43 & & 40 & $0,71\left(^{*}\right)$ & 18,13 & & 41 & $0,59(*)$ & 16,39 \\
\hline & 26 & $0,67\left(^{*}\right)$ & 42,65 & & 42 & $0,64(*)$ & 15,91 & & 50 & $0,41\left(^{*}\right)$ & 11,64 \\
\hline & 32 & $0,52(*)$ & 22,23 & & 44 & $0,54(*)$ & 13,79 & & 51 & $0,37(*)$ & 10,59 \\
\hline & 34 & $0,69(*)$ & 44,87 & & 45 & $0,67\left(^{*}\right)$ & 17,12 & & 54 & $0,62(*)$ & 15,64 \\
\hline & 35 & $0,47\left(^{*}\right)$ & 19,35 & & 46 & $0,43\left(^{*}\right)$ & 12,29 & & 63 & $0,51\left(^{*}\right)$ & 12,27 \\
\hline & 52 & $0,55\left(^{*}\right)$ & 24,34 & & 49 & $0,69\left(^{*}\right)$ & 17,28 & & 66 & $0,31\left(^{*}\right)$ & 10,95 \\
\hline & 61 & $0,66\left(^{*}\right)$ & 38,29 & & 60 & $0,64\left(^{*}\right)$ & 16,25 & & 69 & $0,45\left(^{*}\right)$ & 10,66 \\
\hline & 67 & $0,67\left(^{*}\right)$ & 62,42 & & \multirow[t]{2}{*}{64} & \multirow[t]{2}{*}{$0,49\left(^{*}\right)$} & \multirow[t]{2}{*}{11,34} & & \multirow[t]{2}{*}{71} & \multirow[t]{2}{*}{$0,44(*)$} & \multirow[t]{2}{*}{10,3} \\
\hline & 73 & $0,55\left(^{*}\right)$ & 12,15 & & & & & & & & \\
\hline Sub & & & & Sub & & & & Sub & & & \\
\hline Scale & Item No & $\mathbf{r}_{\mathbf{j} x}$ & $\mathbf{t}$ & Scale & Item No & $\mathbf{r}_{\mathbf{j} x}$ & $\mathbf{t}$ & Scale & Item No & $\mathbf{r}_{\mathrm{j} x}$ & $\mathbf{t}$ \\
\hline \multirow{11}{*}{ 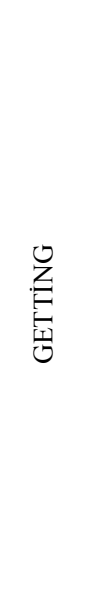 } & 9 & $0,61\left(^{*}\right)$ & 15,75 & \multirow{11}{*}{ 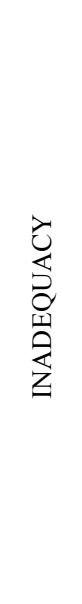 } & 15 & $0,47\left(^{*}\right)$ & 10,54 & \multirow{11}{*}{ 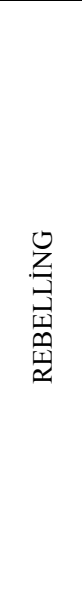 } & 10 & $0,47(*)$ & 10,59 \\
\hline & 25 & $0,41\left(^{*}\right)$ & 10,84 & & 18 & $0,42\left(^{*}\right)$ & 13,42 & & 16 & $0,39(*)$ & 11,44 \\
\hline & 27 & $0,41\left(^{*}\right)$ & 11,64 & & 21 & $0,44\left(^{*}\right)$ & 13,97 & & 24 & $0,38\left(^{*}\right)$ & 10,33 \\
\hline & 30 & $0,41\left(^{*}\right)$ & 10,25 & & 37 & $0,48\left(^{*}\right)$ & 19,73 & & 28 & $0,51\left(^{*}\right)$ & 14,81 \\
\hline & 38 & $0,42\left(^{*}\right)$ & 10,92 & & 48 & $0,47(*)$ & 12,19 & & 33 & $0,39(*)$ & 10,33 \\
\hline & 43 & $0,34\left(^{*}\right)$ & 10,79 & & 56 & $0,51\left(^{*}\right)$ & 10,01 & & 36 & $0,39(*)$ & 10,94 \\
\hline & 47 & $0,62\left(^{*}\right)$ & 16,89 & & 59 & $0,49\left(^{*}\right)$ & 11,34 & & 39 & $0,37\left(^{*}\right)$ & 10,76 \\
\hline & 53 & $0,47\left(^{*}\right)$ & 12,84 & & 62 & $0,39\left(^{*}\right)$ & 10,56 & & 55 & $0,41\left(^{*}\right)$ & 11,51 \\
\hline & 58 & $0,38\left(^{*}\right)$ & 10,31 & & 65 & $0,55\left(^{*}\right)$ & 13,97 & & 57 & $0,42\left(^{*}\right)$ & 10,73 \\
\hline & 70 & $0,39\left(^{*}\right)$ & 10,37 & & 68 & $0,38\left(^{*}\right)$ & 10,54 & & & & \\
\hline & 72 & $0,41\left(^{*}\right)$ & 10,94 & & & & & & & & \\
\hline
\end{tabular}




\subsection{Evaluation of Inventory Points}

Item number in the Turkish form of Children Life Styles is 73 . The scale is 5 point likert scale and there are 14 items in Pleasing sub scale, 9 items in Rebelling sub scale, 11 items in Getting sub scale, 14 items in Controlling sub scale, 10 items in Inadequacy sub scale, 15 items in Socially Useful sub scale. Minimum and maximum points that can be taken from each sub inventory are given. On the other hand, according to these points, determining children life styles and calculation of points are given in Table 4.

Table 4: Calculation of Child Life Styles Inventory Sub Scale

\begin{tabular}{lcccl}
\hline Sub Scale & Total Item & Lowest Score & Higest Score & \multicolumn{1}{c}{ Life style score } \\
\hline Socially Useful & 15 & 15 & 75 & Sub scale score X 1,33 \\
Pleasing & 14 & 14 & 70 & Sub scale score X 1,42 \\
Controlling & 14 & 14 & 70 & Sub scale score X 1,42 \\
Getting & 11 & 11 & 55 & Sub scale score X 1,81 \\
Inadequacy & 10 & 10 & 50 & Sub scale score X 2 \\
Rebelling & 9 & 9 & 45 & Sub scale score X 2,22 \\
\hline
\end{tabular}

In Children Life Styles Inventory, child's life style is determined according to his points from each inventory. As inventory items aren't distributed equally to the sub inventories, formula given in the above table $([100 \div$ Highest score] $\times$ life style score) is used and children's inventory points are calculated equally out of 100 . According to this, coefficients of the sub scales were; Socially Useful sub scale $100 \div 75=1,33$, Pleasing sub scale $100 \div 70=1,42$, Controlling sub scale $100 \div 70=1,42$, Getting sub scale $100 \div 55=1,81$, Inadequacy sub scale $100 \div 50=2$, Rebelling sub scale $100 \div 45=2,22$. For instance, "A Life Styles point of a child who got 60 points from Socially Useful Sub Scale is $60 \times 1,33=80$ ". High score of sub scale determines child's life style. Application process of the inventory continues for 20-30 minutes. It can be applied individually or as groups.

\section{Discussion}

Children Life Styles Inventory was developed by Stiles \& Wilborn and in this study, Psychometric features of the inventory in Turkey is researched. At the end of the study, it was found out that correlation coefficient among original and applied form points was .87 for linguistic equivalence. This result shows that Turkish translated inventory items are similar with the original English ones. At the end of reliability analysis, it was understood that 17 items of Children Life Styles inventory decreased the Cronbach Alpha coefficient and should be removed from the inventory. In Arnold's study (1996) which was on the same issue, inventory items were removed too. In the light of this finding, which supported our study, these items were removed from the inventory. The Turkish form had 73 items and test retest reliability coefficient was .88 , this shows the determination of inventory.

Turkish form's structure and consistence reliability were analyzed. At the end of the explanatory factor analysis, Children Life Styles Inventory had 6 items and it was found that items in the sub scales were consistent with the items in the original inventory. On the other hand, original scale was taken into consideration for the consistence validity study of Children Life Styles Inventory. The inventory gave better data in Turkish reliability and validity study. The reason of this can be that the sampling group of original scale included 381 people between 8 and 11 ages, and the sampling group of Turkish adaptation included 451 people between 14 and 16 ages and the problematic inventory items were removed. In Arnold's study (1996), the inventory gave better results than the original one and inventory items were decreased to 64 .

In the light of these data, factor analysis was applied to confirmatory factor analysis. At the end of DFA, it was found that $\chi^{2}$ (938.94) sd (290) $\left(\chi^{2} / \mathrm{sd}=3.23\right)$ and, RMSEA (.07) RMR (.08) SRMR (.07) GFI (.95) AGFI (.93) CFI (96). These results also show that the structure of the scale was correctly adapted from the original form and corresponded to factor analysis results.

At the end of item analysis, it was found out that Children Life Styles Inventory's corrected item-total point correlations were between .31 and .74 ; inventory's $\mathrm{t}(\mathrm{sd}=327)$ values according to the differences between the points of $\% 27 \mathrm{sub}$ and super groups that were determined according to total points were between $10.01(\mathrm{p}<.01)$ and 73.43 $(\mathrm{p}<.01)$. When $\mathrm{t}$ test results of the differences $\% 27$ sub and super groups' item points were taken into consideration, it was seen that the items' distinguishing power was sufficient. 
Children Life Styles Inventory is prepared with inspiration from Adlerian concepts. In this sense, the inventory tries to determine the life style of children by depending on the basic concepts of Individual Psychology. High points taken from the sub scales of the inventory show the life style adopted by the child. There is not such a scale in Asian countries, and there are a limited number of studies about children life styles; so creating such a scale in Turkish will fill the gap in this field of study and will form a basis for future studies in Asia.

\section{References}

Adler, A. (1964). The Indlvıdual Psychology of Alfred Adler (H. Ansbacher \& R. Ansbacher Eds.) New York: Harper \& Row.

Adler, A. (1993). Psikolojik Aktivite, (Çev: Belkıs Çorakçı). Say Yayınları, İstanbul.

Allen, E. G. S. (2004). Assessing The Adlerian Personality Priorities: A Formal Instrument For Therapeutic Practice, Unpublished Dissertation. University of North Texas, Denton, Texas

Arnold, J. S. O. (1996). A Psychometric Study of Stiles Child Life Style Scale, Unpublished Dissertation, University of North Texas, Denton, Texas.

Baykul, Y. (2000). Istatistik Metod ve Uygulamaları. Anı Yayınları, Ankara.

Büyüköztürk, Ş. (2004). Sosyal Bilimler İçin Veri Analizi El kitabı. Pegem Yayıncılık, Ankara.

Jöreskog, K. G. (1969). A general approach to confirmatory maximum likelihood factor analysis. Psychometrika, 34(2), 183-202. http://dx.doi.org/10.1007/BF02289343

Kern, R. M., Belangee, S. E., \& Eckstein, D. (2004). Early recollections: A guide for practitioners. The Journal of Individual Psychology, 60, 132-140. Retrieved from http://www.utexas.edu/utpress/journals/jaip.html\#602

Kern, R. M., Curlette, W. L., \& Mullis, F. Y. (1984). An overview of the development of a personality instrument to measure Adierian life style. Paper presented to the National Council on Measurement in Education, New Orleans, LA

Kop R., \& Eckstein, D. (2004). Using Early Memory Metaphors and Client- Generated Metaphors in Adlerian $\begin{array}{lllll}\text { Therapy. Journal of Individual } & \text { Psychology, } & 60(2), & \text { 163-174. }\end{array}$ http://www.utexas.edu/utpress/journals/jaip.html \#602

Langfeld, S.D. (1981). Personality Priorities: A Factor Analytic Study, Unpublished Dissertation. University of South Dakota.

Lewis1 A. J., \& Olsson1 C. A. (2011). Early Life Stress and Child Temperament Style as Predictors of Childhood Anxiety and Depressive Symptoms: Findings from the Longitudinal Study of Australian Children Depression Research and Treatment Volume 2011, Article ID 296026. http://dx.doi.org/10.1155/2011/296026

Shulman, B. H., \& Mosak, H. H. (1988). What is the life style? Manual fort he life style assesment, Levittown.

Stiles, K. Wilborn, B. A. (1992). Life Style Instument For Children. Indivldual Psychology Journal, 48(1), 96-105. http://www.utexas.edu/utpress/journals/jaip.html\#602

Şimşek, Ö. (2007). Yapısal Eşitlik Modellemesine Giriş. Ekinoks Yayınları, Ankara. 